\title{
Satellite-derived SST data as a proxy for water temperature in nearshore benthic ecology
}

\author{
Dan A. Smale ${ }^{1}$, Thomas Wernberg ${ }^{1,2, *}$ \\ ${ }^{1}$ School of Plant Biology, University of Western Australia, 35 Stirling Highway, Crawley, Western Australia 6009, Australia \\ ${ }^{2}$ Centre for Marine Ecosystems Research, Edith Cowan University, 270 Joondalup Drive, Joondalup, Western Australia 6027, \\ Australia
}

\begin{abstract}
Satellite-derived sea surface temperatures (SSTs) are increasingly being used as a proxy for water temperature in nearshore marine ecology, but there have been very few evaluations of how accurately SSTs reflect actual temperatures experienced by subtidal organisms. Here, we describe the benthic temperature climatology of 4 coastal locations along a $\sim 1000 \mathrm{~km}$ latitudinal gradient in ocean temperature in Western Australia (WA), and compare temperature records from in situ loggers at 10 to $12 \mathrm{~m}$ depth with records from 2 independent satellite-derived SST datasets over 2 years. Satellite-derived SSTs were significantly correlated with in situ logger data at all locations, which demonstrate their overall ability to detect general patterns of ecological importance. However, SSTs were also significantly different from benthic water temperatures (usually 1 to $2^{\circ} \mathrm{C}$ higher), and they did not adequately detect ecologically important small-scale variability or provide reliable information on temperature extremes. Furthermore, rank orders of the study locations differed between the methodologies, especially in winter. We emphasize the need to carefully consider whether the accuracy and resolution of satellite-derived SSTs are appropriate for the specific ecological hypothesis being tested in nearshore subtidal habitats, and advocate the use of in situ loggers otherwise. We also highlight the suitability of the WA coastline for experimental work on the effects of temperature (and synergistic factors) on marine organisms.
\end{abstract}

KEY WORDS: Benthic climatology · Satellite-derived SST · Temperature gradient · Shallow water habitats

Resale or republication not permitted without written consent of the publisher

\section{INTRODUCTION}

Considerable advances in remote sensing technology over the past few decades have allowed researchers to map sea surface temperature (SST) across the globe at ever increasing spatial and temporal resolutions. Satellite-derived SST data have become a widely used tool for monitoring changes in ocean temperature driven by climate change and have been incorporated into a myriad of biological models and studies (e.g. Littaye et al. 2004, Zainuddin et al. 2006, Muhling et al. 2008). Temperature is a key factor controlling the distribution of species and physiological processes (Schils \& Wilson 2006, O'Connor et al. 2007, Byrne et al. 2009, Staehr \& Wernberg 2009), and easily accessible temperature data for the global ocean has facilitated considerable progress in our under- standing of broad-scale biological patterns. As satellite-derived SSTs are now collected at high spatial and temporal resolutions and are readily available, their use as proxies for water temperature in nearshore benthic habitats has become increasingly popular (Donner et al. 2005, Broitman et al. 2008, Mauna et al. 2008). While this application of SSTs has been useful in explaining ecological patterns, there have been very few detailed comparisons of satellite-derived data and in situ temperature data collected from shallow subtidal habitats. Yet, this information is critical in linking ecological patterns and environmental variation in a mechanistic framework with predictive capacity.

Satellite-derived SST data are obtained by sensing ocean radiation in 2 or more wavelengths, usually in the infrared part of the electromagnetic spectrum, which can then be empirically related to SST. How- 
ever, this measurement is derived from the top 'skin' of seawater ( $0.01 \mathrm{~mm}$ thick) and may not be representative of seawater temperature further down in the water column ('bulk' temperature). The relationship between 'skin' and 'bulk' temperature is strongly influenced by sea state, weather conditions and local oceanography, and has been the focus of many ground-truthing studies (Barton \& Pearce 2006, Pearce et al. 2006). It is clear that, under certain conditions, SST values may be representative of water temperatures to depths of a few meters in the open ocean (Katsaros 2003). Such observations may have prompted the use of satellite-derived SSTs in shallow-water ecological studies. However, in shallow coastal benthic habitats, factors such as tides, waves, water clarity and the thermal properties of the substratum, may influence temperature profiles and possibly reduce the correspondence between SSTs and the temperatures experienced by organisms living near the bottom. Given the severity of likely impacts, there is an increasing need to understand how organisms would respond to the current rate of global change, including ocean warming, and such an understanding is only possible if coupled with accurate environmental data. Here, we compare temperatures measured in situ on subtidal reefs with 2 types of satellite-derived SSTs, with particular reference to variability over space and time, and within the context of nearshore marine ecology. We emphasize that we did not aim to assess the accuracy or precision of satellitederived SSTs; this would have required in situ measurements of temperature from the sea surface, and such studies are numerous in the literature (Yokoyama \& Tanba 1991, Pearce et al. 2006). Rather, this study evaluated the usefulness of SST as a proxy for actual temperature in shallow subtidal habitats at water depths of $\sim 10 \mathrm{~m}$.

The coastal environment of Western Australia (WA) is unique in many ways. The west coast is very extensive (ranging from $15^{\circ}$ to $35^{\circ} \mathrm{S}$ ) but sparsely populated, so that most marine habitats can be considered relatively pristine and largely shaped by natural forces. The coastline is heavily influenced by the Leeuwin Current (LC) (Cresswell \& Golding 1980, Pattiaratchi \& Buchan 1991, Pearce 1991) which, along with latitudinal factors, drives a well-defined temperature gradient. Many temperate marine species are at their northern (warm) distribution limit (Wernberg et al. 2003a, Tuya et al. 2008, Wernberg et al. 2008) and tropical species at their southern (cool) distribution limit (Babcock et al. 1994, Greenstein \& Pandolfi 2008) along this temperate-tropical transition zone. The region therefore has great potential for the conduct of field studies on the effects of temperature on the ecology and physiology of marine organisms. Despite numerous investigations of the offshore oceanographic conditions, envi- ronmental data from the nearshore habitats of the region remain scarce. Our concurrent aim for this study was, therefore, to quantify the climatology and temperature gradient in nearshore subtidal habitats along the coastline of temperate WA.

\section{MATERIALS AND METHODS}

Study site. The study covered 4 locations evenly distributed across $\sim 6^{\circ}$ latitude ( $1000 \mathrm{~km}$ of coastline) of temperate coastline in WA (Fig. 1). Despite considerable distance $(\sim 300 \mathrm{~km})$ between them, these locations are broadly comparable with submerged rocky reefs that run parallel to the coast at distances of $<1$ to $12 \mathrm{~km}$ from the shore (Searle \& Semeniuk 1985). These reefs are all exposed to heavy swells and persistent windinduced waves (Lemm et al. 1999), and all support similar benthic communities dominated by a low standing canopy of the kelp Ecklonia radiata (Wernberg et al. 2003b, Tuya et al. 2008, Wernberg et al. 2008).

In situ logger data. At each location, a 'TidbiT' self-recording temperature logger (Onset Stowaway logger, model TBI32-05+37, accuracy $\pm 0.2^{\circ} \mathrm{C}$ ) was mounted on a stake $\sim 5 \mathrm{~cm}$ above the bottom at 10

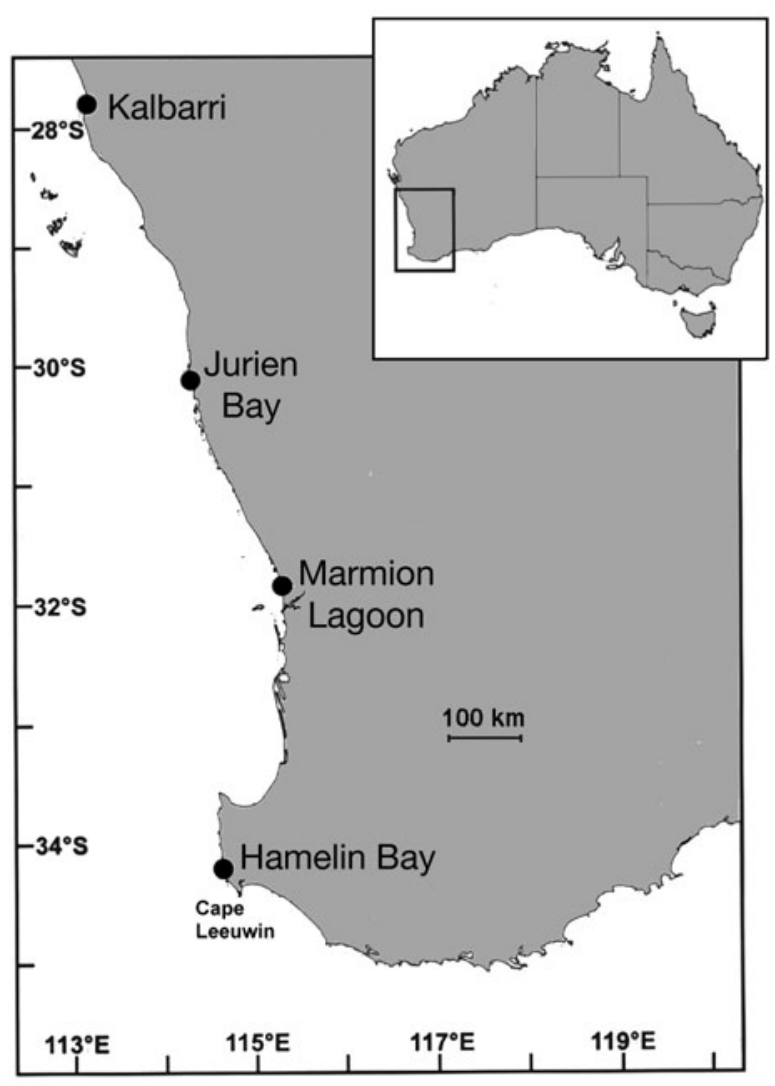

Fig. 1. Map of the 4 study locations along the southwest coastline of Western Australia 
to $12 \mathrm{~m}$ depth at each of 3 reefs separated by $>1 \mathrm{~km}$ in a north-south direction. All 12 loggers were installed by 24 April 2006 and from then on continuously recorded temperature measurements at hourly intervals for 2 yr.

Satellite-derived SST data. Two satellite-derived SST datasets were compared with the logger data. The first dataset was obtained by the advanced very high resolution radiometer (AVHRR) aboard the NOAA series of satellites. SSTs derived by AVHRR have been archived by the Australian Bureau of Meteorology since the 1970s and are now freely available on their website (www.bom.gov.au), which also includes details on the methodologies used to calculate SSTs (www.bom.gov.au/sat/SST/sst.shtml). Daily SST maps of Australian waters were used to manually generate a dataset for each of the 4 study locations. A single pixel (representing $\sim 20 \times 20 \mathrm{~km}$ ) was selected for each study location and, using a simple calibration curve, the colour intensity of the pixel was converted to a temperature value in ${ }^{\circ} \mathrm{C}$. The same pixel for each location was selected from all images.

The second dataset was obtained from the moderateresolution imaging spectroradiometer (MODIS) installed on the Terra and Aqua NASA-operated satellites. This is a relatively new instrument which provides highly accurate SSTs at spatial resolutions of $<1 \mathrm{~km}$. MODIS data were supplied as maximum SSTs within $4 \mathrm{~d}$ periods (bins) for each reef; in contrast to the AVHRR data, a value for SST above each reef was possible with MODIS due to the increased resolution of the data. The mean maximum SST $( \pm \mathrm{SD})$ for each location was calculated from the 3 replicate reefs within each location. Data were again supplied by the Australian Bureau of Meteorology.

It is not possible to obtain satellite-derived SSTs during periods of thick cloud cover. Consequently, there were no data for some days in the AVHRR datasets and for some $4 \mathrm{~d}$ bins in the MODIS dataset. This problem was most prevalent at Hamelin Bay, but even here data were available for $>90 \%$ of all sampling occasions (pairwise tests were not conducted for days when satellite-derived SSTs were unavailable). The use of 2 distinct satellite-derived SST datasets allowed us to compare the 2 different instruments (AVHRR and MODIS) and 2 different data types (daily mean temperatures and maximum values from $4 \mathrm{~d}$ bins).

Data analysis. Logger data were initially used to characterize the thermal environment of our study locations and general patterns across seasons, years and the study region as a whole. Differences in daily mean temperatures, maxima and minima among locations (fixed) and reefs (random and nested within locations) were tested with ANOVAs on untransformed logger data for each year of study. Subsequently, for comparisons with AVHRR-derived data, daily means from the in situ loggers were calculated and then averaged across the 3 replicate reefs at each location. This generated a single value for each location and day of study. For comparisons with the MODIS-derived data, logger data were arranged into corresponding $4 \mathrm{~d}$ bins and the maximum values recorded by each logger were extracted. Means $( \pm \mathrm{SD})$ of the 3 loggers at each location were then compared with the MODIS data. Pearson's r values were used to indicate the strength of the correlation between logger and satellite-derived data, while differences were tested with paired $t$-tests.

Seasonal comparisons were conducted by averaging daily mean temperatures across the 4 seasons for both in situ and satellite-derived data. Finally, periods of temperature maxima, which are thought to be of particular ecological importance, were analyzed from the logger data collected at each location. The proportion of the daily means that were greater than the upper range of temperatures recorded in the study region (i.e. $18-25^{\circ} \mathrm{C}$ ) were also calculated and plotted for each location.

\section{RESULTS}

\section{General climatology of study locations}

Our 4 study locations ranged in mean annual temperature by $\sim 2^{\circ} \mathrm{C}$ (Table 1 ). Generally, sea temperature on the subtidal reefs, as described by daily means, maxima and minima, increased with decreasing latitude; hence, the study locations were arranged along a latitudinal/temperature gradient (Fig. 2). As would be expected for a mid-latitude temperate study region, patterns in sea temperature were highly seasonal (Fig. 2). The daily mean temperature ranged by 6.9, $7.8,7.1$ and $5.8^{\circ} \mathrm{C}$ at Kalbarri, Jurien Bay, Marmion Lagoon and Hamelin Bay, respectively. Overall, sea temperatures ranged by $>10^{\circ} \mathrm{C}$, from a winter minimum of $15.7^{\circ} \mathrm{C}$ at Jurien Bay to a summer maximum of $26.9^{\circ} \mathrm{C}$ at Kalbarri.

Interestingly, while the latitudinal/temperature gradient persisted for annual daily mean temperatures, maximum daily means and annual maxima, it was not as clear for minimum daily mean temperatures or annual minima. For instance, the minimum daily mean recorded at Marmion Lagoon was lower than that at Hamelin Bay, and the absolute minimum reading obtained in 2006/2007 was lower at Jurien than at either Marmion Lagoon or Hamelin Bay (Table 1). Nevertheless, overall daily mean temperatures, maxima and minima were strongly significantly different among locations, while no differences were observed among replicate reefs within each location during both 
Table 1. Summary of temperature data recorded by loggers at each of the 4 locations for each year of study. Mean values are averages of 3 replicate loggers at each location $( \pm$ SD). Maxima and minima represent the highest and lowest temperatures recorded at any logger at each location during each year of study. Variability among hourly and daily logger readings are shown as CVs

\begin{tabular}{|c|c|c|c|c|c|c|c|}
\hline & \multicolumn{3}{|c|}{$\begin{array}{c}\text { Temperature }\left({ }^{\circ} \mathrm{C}\right)- \\
\text { Daily mean }\end{array}$} & \multicolumn{2}{|c|}{ Annual } & \multicolumn{2}{|c|}{$\begin{array}{l}\text { Max. CV between } \\
\text { loggers }(\%)\end{array}$} \\
\hline & Annual & $\begin{array}{c}\text {-Daily mean } \\
\text { Max. }\end{array}$ & Min. & $\begin{array}{l}\text { Ar } \\
\text { Max. }\end{array}$ & Min. & $\begin{array}{r}\log 9 \\
\text { Hourly }\end{array}$ & \\
\hline \multicolumn{8}{|c|}{ Apr 2006-Apr 2007} \\
\hline Kalbarri & $21.88 \pm 0.05$ & $24.16 \pm 0.03$ & $19.26 \pm 0.07$ & 24.32 & 18.51 & 9.1 & 1.8 \\
\hline Jurien & $20.73 \pm 0.04$ & $23.71 \pm 0.07$ & $17.13 \pm 0.82$ & 24.31 & 15.67 & 6.3 & 6.0 \\
\hline Marmion & $20.27 \pm 0.02$ & $23.30 \pm 0.10$ & $16.57 \pm 0.41$ & 23.72 & 15.73 & 6.4 & 4.8 \\
\hline Hamelin & $19.49 \pm 0.03$ & $21.62 \pm 0.07$ & $16.81 \pm 0.07$ & 21.97 & 16.48 & 4.8 & 2.8 \\
\hline \multicolumn{8}{|c|}{ Apr 2007-Apr 2008} \\
\hline Kalbarri & $21.89 \pm 0.01$ & $26.13 \pm 0.03$ & $19.69 \pm 0.03$ & 26.91 & 19.30 & 3.4 & 0.7 \\
\hline Jurien & $20.93 \pm 0.12$ & $24.94 \pm 0.19$ & $17.45 \pm 0.62$ & 26.17 & 16.21 & 9.9 & 4.9 \\
\hline Marmion & $20.14 \pm 0.10$ & $23.73 \pm 0.14$ & $16.81 \pm 0.16$ & 24.10 & 15.89 & 5.7 & 4.2 \\
\hline Hamelin & $19.45 \pm 0.04$ & $22.61 \pm 0.10$ & $16.78 \pm 0.17$ & 23.13 & 16.50 & 4.0 & 3.2 \\
\hline
\end{tabular}

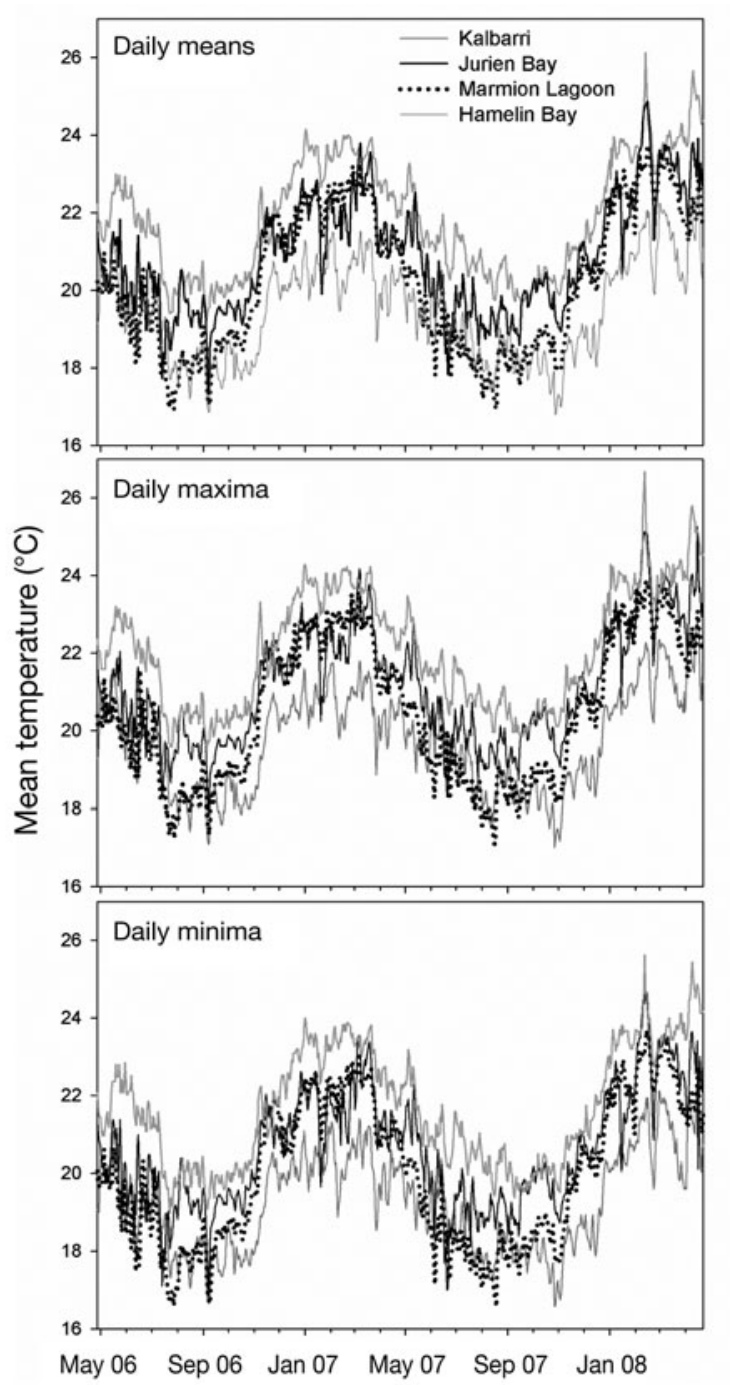

Fig. 2. Daily mean, maximum and minimum temperatures for each study location throughout the period of data collection (2006-2008). Values are means of 3 replicate loggers years of study (Table 2). Subsequent post-hoc testing (Tukey's pairwise tests) indicated that Kalbarri > Jurien Bay > Marmion Lagoon > Hamelin Bay with respect to daily mean temperatures, maxima and minima.

All locations showed strong and similar seasonal variation, as annual minimum temperatures were consistently recorded during the austral winter (JuneAugust) and annual maxima were observed during the austral summer (December-February) (Fig. 2). Seasonal mean temperatures (both years combined) were considerably lower in winter and spring than in summer and autumn at all sites, as would be expected (Table 3). Within each site, maximum and minimum seasonal mean temperatures differed by 2.8, 2.5, 3.8 and $2.1^{\circ} \mathrm{C}$ at Kalbarri, Jurien Bay, Marmion Lagoon and Hamelin Bay, respectively. The latitudinal/temperature gradient was apparent from the rank orders of seasonal means for spring (September-November) and autumn (March-May), but not for winter or summer (Table 3). During winter, Hamelin Bay was slightly warmer than Marmion Lagoon, while Marmion Lagoon was warmer than Jurien Bay during summer, despite the latter being $\sim 300 \mathrm{~km}$ further north.

Variation among loggers at replicate reefs within locations was generally minimal, as evidenced by low maximum coefficients of variation (CVs) (Tables 1 \& 3). However, comparisons among locations showed that variability among replicate reefs (i.e. across daily or hourly measurements) was consistently greatest at Jurien Bay and consistently lowest at Kalbarri. Smallscale temporal variability was also generally low. For example, diurnal variability was typically $<1^{\circ} \mathrm{C}$ and variation in daily means for consecutive days was minimal (Table 1). However, we observed occasional short-term spikes in temperature, which considerably increased temporal variation. For example, in Febru- 
Table 2. Results of nested ANOVA for differences in daily mean, minimum and maximum temperatures (untransformed) among locations and reefs within locations, for each year of study. KAL: Kalbarri; JUR: Jurren; MAR: Marmion; HAM: Hamelin

\begin{tabular}{|c|c|c|c|c|}
\hline Source & df & MS & $F$ & $\mathrm{p}$ \\
\hline \multicolumn{5}{|c|}{ Year 1 (Apr 06-Apr 07) } \\
\hline \multicolumn{5}{|l|}{ Daily mean } \\
\hline Location & 3 & 1099 & 1303 & $<0.001$ \\
\hline Reef(location) & 8 & 0.84 & 0.42 & 0.908 \\
\hline Error & 4368 & 1.99 & & \\
\hline \multicolumn{5}{|c|}{$\begin{array}{l}\text { Post-hoc comparison of locations }(\mathrm{p}<0.05) \text { : } \\
\text { KAL }>\text { JUR }>\text { MAR }>\text { HAM }\end{array}$} \\
\hline \multicolumn{5}{|l|}{ Daily max. } \\
\hline Location & 3 & 1072 & 1667 & $<0.001$ \\
\hline Reef(location) & 8 & 0.64 & 0.32 & 0.958 \\
\hline Error & 4368 & 2.00 & & \\
\hline \multicolumn{5}{|c|}{$\begin{array}{l}\text { Post-hoc comparison of locations }(p<0.05) \text { : } \\
\text { KAL }>\text { JUR }>\text { MAR }>\text { HAM }\end{array}$} \\
\hline \multicolumn{5}{|l|}{ Daily min. } \\
\hline Location & 3 & 1098 & 903 & $<0.001$ \\
\hline Reef(location) & 8 & 1.22 & 0.59 & 0.787 \\
\hline Error & 4368 & 2.06 & & \\
\hline \multicolumn{5}{|c|}{$\begin{array}{l}\text { Post-hoc comparison of locations }(\mathrm{p}<0.05) \text { : } \\
\text { KAL }>\text { JUR }>\text { MAR }>\text { HAM }\end{array}$} \\
\hline \multicolumn{5}{|c|}{ Year 2 (Apr 07-Apr 08) } \\
\hline \multicolumn{5}{|c|}{ Daily mean } \\
\hline Location & 3 & 1211 & 464 & $<0.001$ \\
\hline Reef(location) & 8 & 2.60 & 0.97 & 0.454 \\
\hline Error & 4368 & 2.67 & & \\
\hline \multicolumn{5}{|c|}{$\begin{array}{l}\text { Post-hoc comparison of locations }(\mathrm{p}<0.05) \text { : } \\
\text { KAL }>\text { JUR }>\text { MAR }>\text { HAM }\end{array}$} \\
\hline \multicolumn{5}{|l|}{ Daily max. } \\
\hline Location & 3 & 1190 & 477 & $<0.001$ \\
\hline Reef(location) & 8 & 2.49 & 0.92 & 0.497 \\
\hline Error & 4368 & 2.71 & & \\
\hline \multicolumn{5}{|c|}{$\begin{array}{l}\text { Post-hoc comparison of locations }(p<0.05) \text { : } \\
\text { KAL }>\text { JUR }>\text { MAR }>\text { HAM }\end{array}$} \\
\hline \multicolumn{5}{|l|}{ Daily min. } \\
\hline Location & 3 & 1236 & 408 & $<0.001$ \\
\hline Reef(location) & 8 & 3.02 & 1.11 & 0.355 \\
\hline Error & 4368 & 2.73 & & \\
\hline $\begin{array}{l}\text { Post-hoc comp } \\
\text { KAL }>\text { JUR }>N\end{array}$ & $\begin{array}{l}\text { ison of } \\
\mathrm{R}>\mathrm{HA}\end{array}$ & ations & 0.05): & \\
\hline
\end{tabular}

ary 2008, a noteworthy temperature spike was recorded at all 4 locations, to varying extents (Fig. 3). The signal was strongest at Kalbarri, as during a $3 \mathrm{~d}$ period, the temperature at all 3 reefs increased by almost $3^{\circ} \mathrm{C}$ to $>26.5^{\circ} \mathrm{C}$, before returning and stabilizing at a more 'usual' temperature of $\sim 24^{\circ} \mathrm{C}$ (Fig 3). Occasionally, discrete thermal events were detected at all study locations, and these often occurred simultaneously at all locations, perhaps suggesting that the same broadscale drivers, such as storm events or sustained solar radiation on surface waters, affect the entire study region. For instance, over a 20 d period in December
2006, mean daily temperatures increased by $\sim 2^{\circ} \mathrm{C}$ at all study locations, representing a temperature increase of ca. one-third of the total annual variation.

Measures of extreme upper temperatures also changed along the latitudinal gradient. For example,

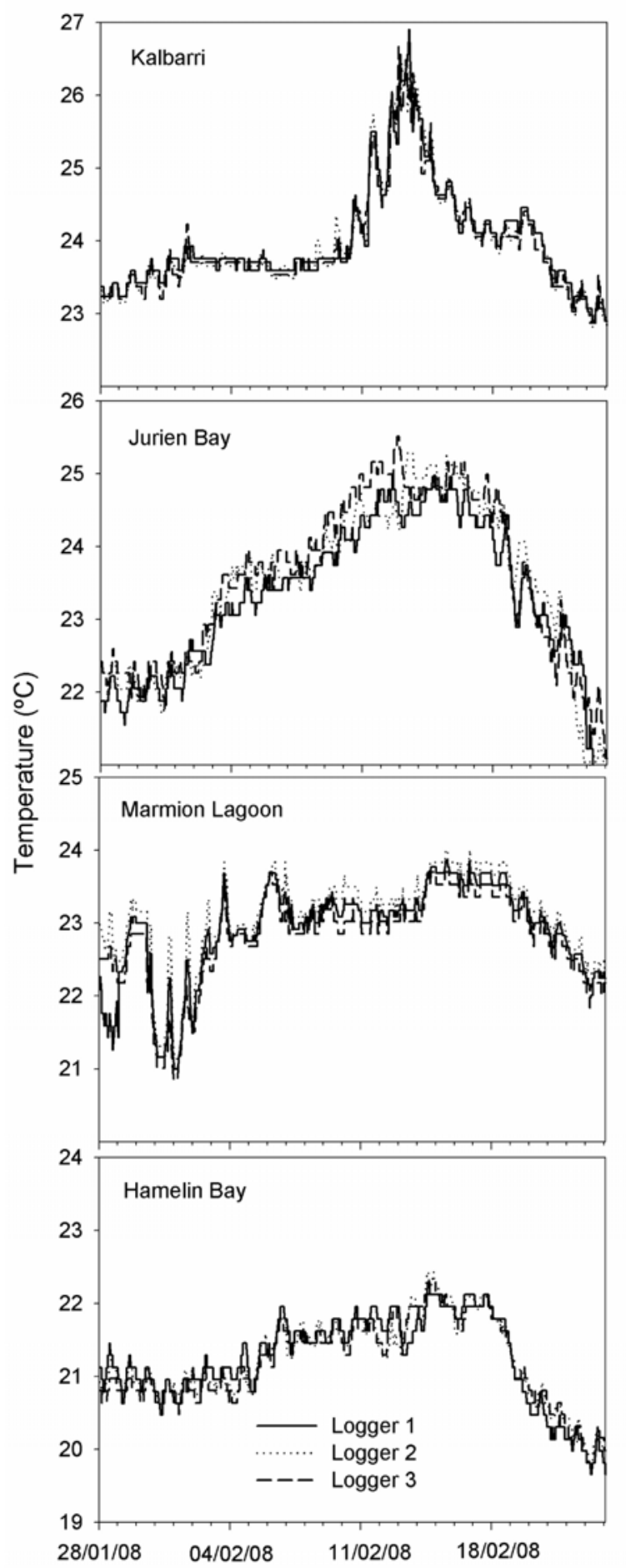

Fig. 3. Short-term temperature spikes recorded at all locations in February 2008. Plots are hourly measurements collected by each logger during the thermal event 
Table 3. Daily mean, maximum and minimum temperatures, and maximum SDs among loggers and between consecutive days for each season ( 2 yr combined) at each of the study locations. Mean values are averages of 3 replicate loggers at each location $( \pm \mathrm{SD})$. Maxima and minima represent the highest and lowest temperatures recorded at any logger at each location during each season. Variability among loggers and between consecutive days are shown as CVs

\begin{tabular}{|c|c|c|c|c|c|}
\hline & \multicolumn{3}{|c|}{ Temperature $\left({ }^{\circ} \mathrm{C}\right)$} & \multicolumn{2}{|c|}{$\begin{array}{l}\text { Max. CV between } \\
\text { loggers (\%) }\end{array}$} \\
\hline & $\begin{array}{l}\text { Seasonal daily } \\
\text { mean (rank) }\end{array}$ & $\begin{array}{l}\text { Seasonal } \\
\text { max. }\end{array}$ & $\begin{array}{l}\text { Seasonal } \\
\text { min. }\end{array}$ & Hourly & Daily \\
\hline \multicolumn{6}{|c|}{ Winter (Jun-Aug) } \\
\hline Kalbarri & $20.84 \pm 0.04(1)$ & 22.98 & 18.92 & 0.9 & 1.6 \\
\hline Jurien & $19.51 \pm 0.18(2)$ & 21.93 & 16.21 & 5.8 & 5.2 \\
\hline Marmion & $18.40 \pm 0.06$ & 21.61 & 15.73 & 4.5 & 4.1 \\
\hline Hamelin & $18.75 \pm 0.11$ & 20.85 & 16.96 & 3.0 & 4.4 \\
\hline \multicolumn{6}{|c|}{ Spring (Sep-Nov) } \\
\hline Kalbarri & $20.48 \pm 0.03$ & 23.41 & 18.99 & 0.7 & 2.4 \\
\hline Jurien & $19.89 \pm 0.06(2)$ & 22.73 & 15.67 & 6.1 & 2.7 \\
\hline Marmion & $19.08 \pm 0.06$ & 22.62 & 16.21 & 2.8 & 3.4 \\
\hline Hamelin & $18.32 \pm 0.07$ & 21.11 & 16.48 & 1.6 & 3.0 \\
\hline \multicolumn{6}{|c|}{ Summer (Dec-Feb) } \\
\hline Kalbarri & $23.23 \pm 0.04(1)$ & 26.91 & 20.72 & 0.9 & 2.6 \\
\hline Jurien & $22.00 \pm 0.13$ & 25.51 & 19.22 & 3.4 & 3.7 \\
\hline Marmion & $22.07 \pm 0.20(2)$ & 24.01 & 19.80 & 4.3 & 3.4 \\
\hline Hamelin & $20.34 \pm 0.03(4)$ & 22.43 & 17.73 & 2.1 & 2.5 \\
\hline \multicolumn{6}{|c|}{ Autumn (Mar-May) } \\
\hline Kalbarri & $22.98 \pm 0.04(1)$ & 25.85 & 18.51 & 1.7 & 1.5 \\
\hline Jurien & $21.94 \pm 0.13(2)$ & 26.17 & 18.26 & 4.6 & 4.2 \\
\hline Marmion & $21.28 \pm 0.04$ & 23.84 & 18.34 & 2.5 & 2.8 \\
\hline Hamelin & $20.44 \pm 0.13$ & 23.13 & 18.08 & 3.3 & 5.1 \\
\hline
\end{tabular}

Seasonal means derived by the AVHRR instrument were, overall, also slightly higher than those derived by the loggers, although the rank of locations based on temperature did not differ between the 2 datasets for spring or autumn. However, differences in the rank order were observed for summer and winter seasonal mean temperatures. While the satellitederived SST data suggested that Jurien Bay was the coolest location during winter, the logger data showed that the shallow subtidal Marmion Lagoon was marginally the coolest location. Similarly, Marmion Lagoon was ranked second based on summer seasonal mean temperatures in the logger-derived dataset but ranked third in the AVHRR-derived dataset (Tables 3 \& 4).

Compared with the AVHRR data, data collected by the MODIS instrument, analyzed as maximum temperatures within $4 \mathrm{~d}$ bins, were less well correlated with in situ logger data (Fig. 6, Table 4). Nevertheless, correlations were significant and ranged from 0.90 at Marmion Lagoon to 0.53 at Hamelin Bay. As with the AVHRR$\sim 45 \%$ of daily mean temperatures were $>22^{\circ} \mathrm{C}$ at Kalbarri, compared with $\sim 23 \%$ at Jurien Bay and Marmion Lagoon and only $2 \%$ at Hamelin Bay (Fig. 4). Interestingly, a clear north-south divide was evident in the number of daily mean temperatures $>19^{\circ} \mathrm{C}$ (>90\% of daily means at Kalbarri and Jurien, compared with $\sim 60 \%$ of daily means at Marmion Lagoon and Hamelin Bay), which may be of ecological importance (see 'Discussion').

\section{Satellite-derived vs. logger-derived data}

The satellite-derived SST data gathered by the AVHRR instrument was significantly correlated with the in situ logger data at all locations, with the minimum correlation (Pearson's) of $\mathrm{r}=0.85$ being observed at Hamelin Bay (Fig. 5, Table 4). However, the datasets were also significantly different: the AVHRR-derived temperatures were generally greater than those recorded by the loggers (Table 4), as evidenced by AVHRR-derived annual means, which were $1-2^{\circ} \mathrm{C}$ greater at each location. However, the rank of locations by annual mean temperature did not vary between the remote and the in situ methodologies (Table 4). derived temperatures, MODIS data were significantly different from the logger data, and were higher at Kalbarri, Jurien Bay and Marmion but lower at Hamelin Bay (Table 4). Furthermore, SSTs were more variable in space than logger-derived temperatures, as evidenced by significantly greater SDs among replicate measurements ( 1 km apart) within each location

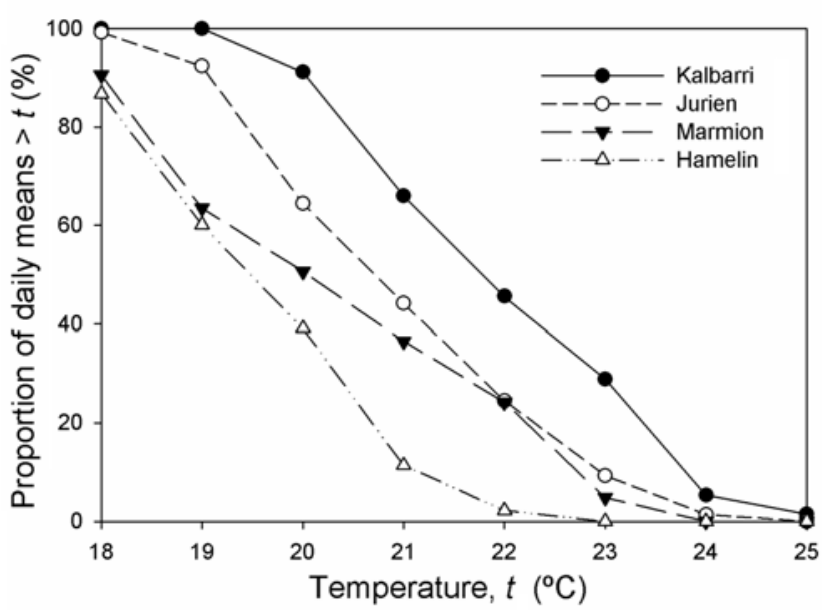

Fig 4. Percentage of daily mean temperatures $>18$ to $25^{\circ} \mathrm{C}$ (whole integers) for each location 

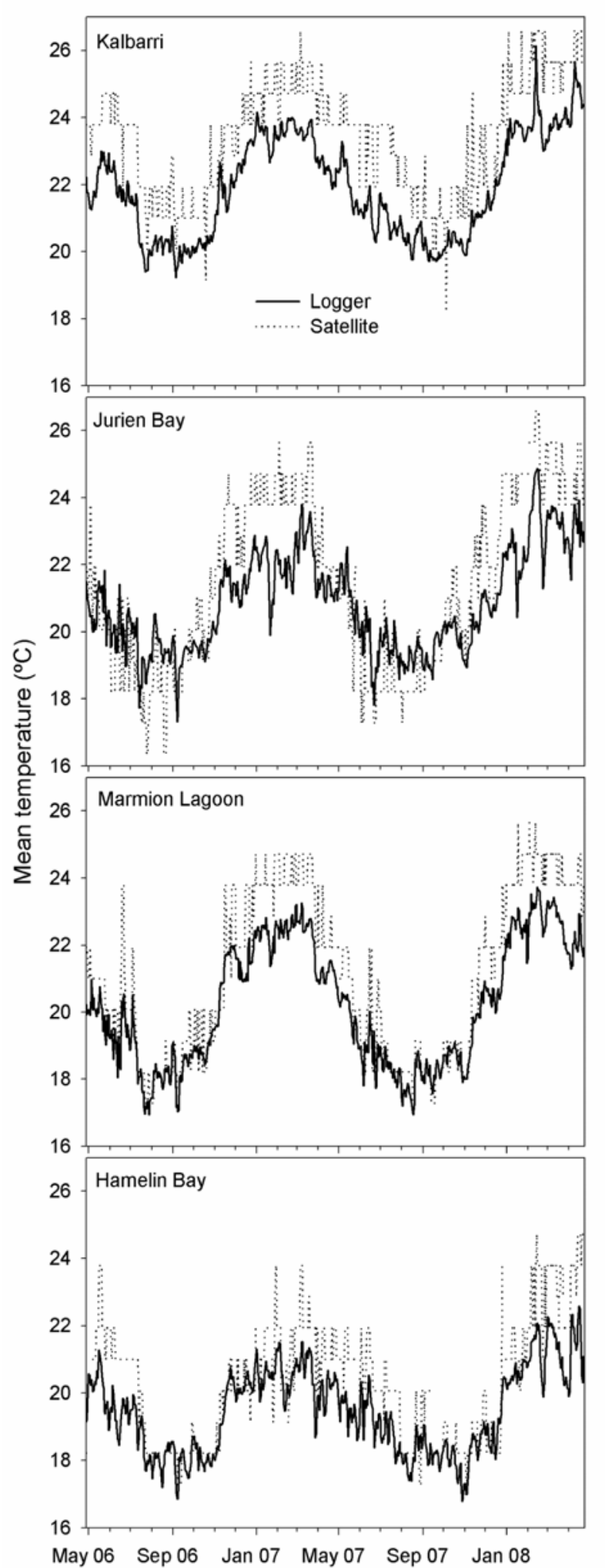

Fig. 5. Sea temperatures recorded by in situ loggers (daily means) and satellite-derived sea surface temperatures (SSTs) obtained by the advanced very high resolution radiometer (AVHRR) (daily means) at each study location throughout the study (2006-2008)

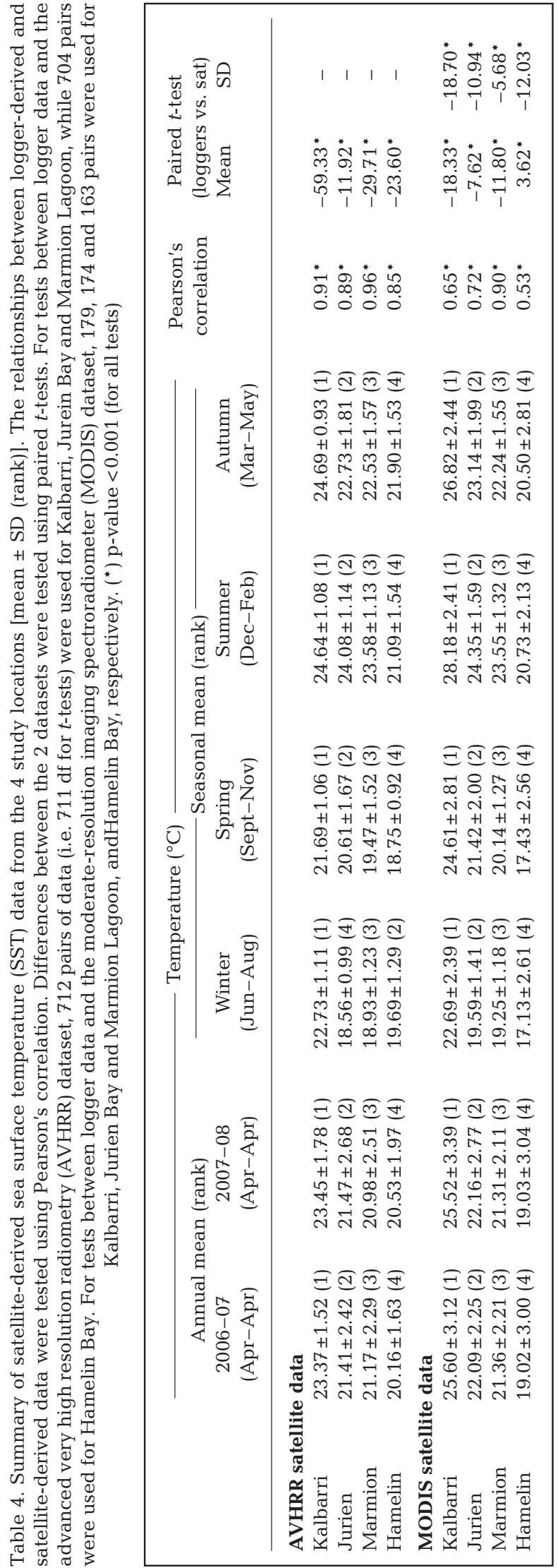



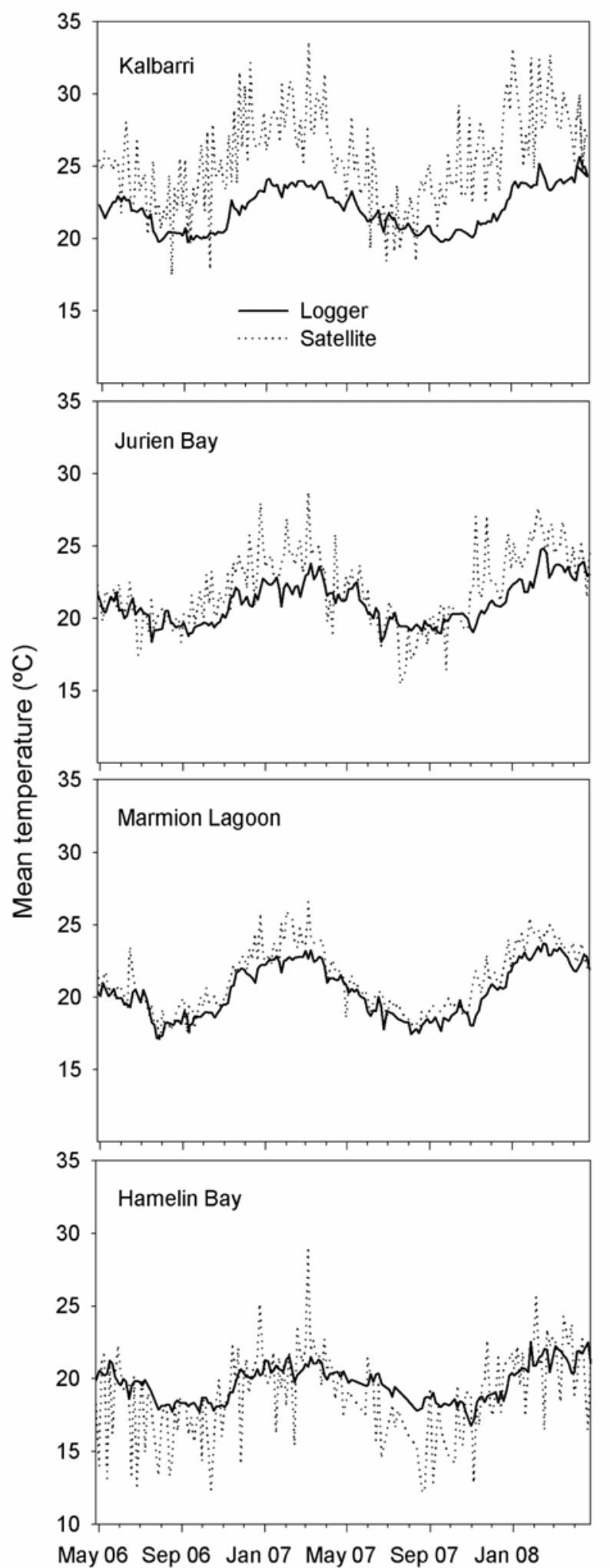

Fig. 6. Sea temperatures recorded by in situ loggers (maxima from $4 \mathrm{~d}$ bins) and satellite-derived sea surface temperatures (SSTs) obtained by the moderate resolution imaging spectroradiometer (MODIS) (maxima from $4 \mathrm{~d}$ bins) at each study location throughout the study (2006-2008)
(Tables 3 \& 4). Despite these differences in actual mean temperatures and in variability, there were no differences between the 2 methodologies in terms of the rank of locations based on annual daily mean temperatures (Table 4).

Seasonal mean temperatures derived by the MODIS instrument were again slightly higher than those derived from the loggers, with the exception of the Hamelin Bay location. Here, MODIS-derived means were $\sim 1^{\circ} \mathrm{C}$ lower than the logger values during winter and spring (Table 4). Interestingly, the rank of the locations based on seasonal mean temperature remained constant through the seasons in the MODIS dataset, in contrast to both the AVHRR and logger datasets.

\section{DISCUSSION}

\section{General climatology of study locations}

The study region is strongly influenced by the Leeuwin Current (LC), which is a unique poleward flowing eastern boundary current that carries warm water along the coast of WA (Pearce 1991). As a result, the coastal waters off WA are warmer in winter than eastern boundary waters at comparable latitudes off South Africa and South America. Moreover, the LC suppresses wind-driven upwelling (Pearce 1991), so that surface waters remain clear and comparatively nutrient-poor (Waite et al. 2007, Koslow et al. 2008).

This unique oceanography was evidenced in the current study in 2 ways. First, as a result of elevated winter temperatures, seasonal variation in mean daily temperatures was low at all study locations, with differences between summer and winter averages of $\sim 2^{\circ} \mathrm{C}$. For instance, winter temperatures at Hamelin Bay $\left(34^{\circ} \mathrm{S}\right)$ were 6 to $9^{\circ} \mathrm{C}$ warmer than those recorded at the Cape of Good Hope (also at $34^{\circ} \mathrm{S}$ ) on the west coast of South Africa (McQuaid \& Branch 1984), again highlighting the considerable effect of the LC on the coastal system of WA.

Second, annual and seasonal temperature minima did not vary along the latitudinal cline as predictably as the mean temperatures or the maxima. The lowest temperature in the first year of study was recorded at Jurien Bay and the absolute minimum for the second year of study was observed at Marmion Lagoon, rather than Hamelin Bay. Although the daily minima still generally significantly decreased with latitude, the unintuitive pattern of extreme minima with latitude may be of ecological importance and should be considered in future ecological studies conducted in the region, particularly for species with tropical affinity. We observed a relative lack of depression in minimum temperatures at Hamelin Bay, which was almost cer- 
tainly driven by the LC. The main flow of the LC runs some $18 \mathrm{~km}$ offshore from the Perth metropolitan area ( 12 km west of Marmion Lagoon), which increases offshore winter sea temperatures by up to 3 to $4^{\circ} \mathrm{C}$ (Pearce et al. 2006). Further south, the LC tracks closer inshore before deviating eastwards along the Southern Australian coastline (Pearce 1991, Smith et al. 1991, Waite et al. 2007). Therefore, the LC may have had greater influence at Hamelin Bay than at Marmion Lagoon, as evidenced by relatively elevated winter sea temperatures. What remains unclear, however, is the degree of inter-annual variability in these patterns and to what extent these observations were driven by small-scale eddies of the LC. The oceanographic and biological importance of such deviations from the main flow of the LC has gained recognition in recent years (Koslow et al. 2008, Meuleners et al. 2008).

Nonetheless, benthic climatology clearly shifted along the latitudinal gradient, in terms of both mean water temperature and extremes of upper and (to a lesser degree) lower temperatures. Periods of extreme temperatures (i.e. winter minima and summer maxima) are of great ecological importance. For example, the kelp Ecklonia radiata, which is a key habitat-forming species within the warm-temperate ecosystem, is at the northern limit of its range at Kalbarri. Its growth and productivity are known to be adversely affected at temperatures $>19^{\circ} \mathrm{C}$ (Kirkman 1984, Hatcher et al. 1987), yet $>90 \%$ of daily means at both Jurien Bay and Kalbarri were above this threshold. In addition, we observed short-lived spikes in temperature of $\sim 3^{\circ} \mathrm{C}$ at both locations, which raised water temperatures on the subtidal reefs to $>25^{\circ} \mathrm{C}$. This suggests that the population is thermally stressed during extreme events, and any increase in the frequency and/or duration of such events could affect the population's ability to grow, reproduce, and undergo post-disturbance recovery.

Similarly, minimum winter temperature may be a controlling factor in the poleward range expansion of warm-water species. For example, in Eastern Australia, a recent range expansion of the habitat-altering sea urchin Centrostephanus rodgersii into Tasmanian waters has been partly driven by winter sea temperatures exceeding the cold threshold for its larval development (Ling 2008, Ling et al. 2008). More locally, studies on the physiology and historical distributions of warm-water reef-building corals suggest that any poleward migrations along the WA coastline would be largely driven by increased winter sea temperatures and a strengthening of the LC (Greenstein \& Pandolfi 2008). Even today, there are many warm-water reef corals found at high latitudes in WA (Greenstein \& Pandolfi 2008), perhaps partly due to the relatively 'warm' winter temperatures experienced along the coastline. Therefore, the latitudinal cline in both means and extremes of temperature in our study region will provide a valuable framework for detecting and investigating the effects of a warming climate.

The 4 study locations were broadly distributed along a latitudinal/temperature gradient, which ranged by $\sim 2^{\circ} \mathrm{C}$ in terms of mean daily temperatures. Crucially, other environmental factors that may influence benthic assemblages at these locations, such as nutrient levels (Pearce 1991, Lourey et al. 2006), light (Staehr \& Wernberg 2009), grazing pressure (Vanderklift \& Kendrick 2004, Wernberg et al. 2008), discrete thermal events (present study), the availability of hard substrata and exposure to oceanic swells (Wernberg \& Thomsen 2005), do not co-vary substantially with latitude and temperature. In addition, the locations are broadly similar in their ecology; they are characterized by patches of Ecklonia radiata and many dominant species span the entire latitudinal cline (Tuya et al. 2008, Staehr \& Wernberg 2009). Therefore, with the absence of confounding factors and the presence of key taxa throughout the region, the warm temperate coastline of WA represents an ideal natural laboratory for investigating the interactive effects of temperature on complex ecological processes.

\section{Satellite-derived vs. logger-derived data}

Satellite-derived SSTs are undoubtedly a useful tool for modern marine ecologists. While they have been used to model and predict biological processes in the open ocean for many years, only recently have they been applied as proxies for temperatures influencing benthic organisms in subtidal habitats. In our study, both satellite-derived datasets were significantly correlated with logger data collected from hard substrata at $\sim 10 \mathrm{~m}$ depth. Therefore, for broad-scale ecological studies, it may be acceptable to infer benthic climatology from SSTs.

However, satellite-derived SSTs are collected from a thin boundary layer at the air-sea interface, and increasingly deviate from actual sea temperatures with increasing water depth (Katsaros 2003). Therefore, as our study showed, satellite-derived SSTs are likely to be significantly different from actual water temperatures influencing shallow subtidal habitats. Within the context of our study, the rank order of our study locations was not consistent between the logger data and the satellite-derived datasets. Such deviations could have important implications for interpreting the results of comparative experiments on the effects of ambient temperature on the physiology or ecology of marine organisms in the region. For instance, if benthic climatology were described with satellite-derived data alone, the importance of warmer winter temperatures 
at Hamelin Bay would be under-appreciated and a certain degree of explanatory power would be lost.

In addition, linking physiology with ecology within a changing climate will require accurate records of temperature minima and maxima, and of the duration of extreme events, which are likely to be at least as important as mean temperature values. Describing benthic climatology solely with satellite-derived SST data negates an understanding of small-scale variability in temperature across both time and space. As discussed above, we detected short-term fluctuations in water temperatures surrounding subtidal reefs that may have important ecological implications, but such fine-resolution information is only obtainable with in situ recorders, not with remote sensing technology.

To conclude, there is a current lack of experimental field studies on the effects of temperature and other climate change-related variables on the structure of marine communities (Harley et al. 2006). Extensive, relatively homogenous coastlines with clearly defined temperature gradients, such as in WA, provide excellent opportunities for in situ ecological manipulations that will improve our understandings of temperaturerelated processes. Our results highlight the usefulness of satellite-derived SSTs as proxies for water temperature in shallow benthic habitats, but also demonstrate the importance of the additional information gained from in situ temperature loggers particularly in relation to short-term peak events. We recommend that, rather than employing remote-sensing technology as a matter of course, benthic ecologists consider whether the accuracy of the information is actually appropriate for, and commensurable with, the ecological questions they ask.

Acknowledgements. We thank M. Steber from the Information Access Division of Landgate, WA, for providing data from, and information on, remote sensing sources. This study was funded by Australian Research Council Discovery grant DP555929 to T.W.

\section{LITERATURE CITED}

Babcock RC, Wills BL, Simpson CJ (1994) Mass spawning of corals on a high latitude coral reef. Coral Reefs 13:161-169

Barton I, Pearce A (2006) Validation of GLI and other satellitederived sea surface temperatures using data from the Rottnest Island ferry, Western Australia. J Oceanogr 62: 303-310

Broitman BR, Blanchette CA, Menge BA, Lubchenco J and others (2008) Spatial and temporal patterns of invertebrate recruitment along the west coast of the United States. Ecol Monogr 78:403-421

Byrne M, Ho M, Selvakumaraswamy P, Nguyen HD, Dworjanyn SA, Davis AR (2009) Temperature, but not $\mathrm{pH}$, compromises sea urchin fertilization and early development under near-future climate change scenarios. Proc R Soc Lond B 276:1883-1888
Cresswell GR, Golding TJ (1980) Observations of a southflowing current in the southeastern Indian Ocean. DeepSea Res II 27:449-466

> Donner SD, Skirving WJ, Little CM, Oppenheimer M, HoeghGuldberg O (2005) Global assessment of coral bleaching and required rates of adaptation under climate change. Glob Change Biol 11:2251-2265

Greenstein BJ, Pandolfi JM (2008) Escaping the heat: range shifts of reef coral taxa in coastal Western Australia. Glob Change Biol 14:513-528

- Harley CDG, Hughes AR, Hultgren KM, Miner BG and others (2006) The impacts of climate change in coastal marine systems. Ecol Lett 9:228-241

> Hatcher BG, Kirkman H, Wood WF (1987) Growth of the kelp Ecklonia radiata near the northern limit of its range in Western Australia. Mar Biol 95:63-73

Katsaros KB (2003) Satellite versus in situ measurements at the air-sea interface. In: Potter TD, Colman BR (eds) Handbook of weather, climate and water. John Wiley \& Sons, New York

Kirkman H (1984) Standing stock and production of Ecklonia radiata (C.Ag.) J. Agardh. J Exp Mar Biol Ecol 76:119-130

Koslow JAS, Pesant S, Feng M, Pearce A and others (2008) The effect of the Leeuwin Current on phytoplankton biomass and production off Southwestern Australia. J Geophys Res 113:C07050 doi:10.1029/2007JC004102

> Lemm AJ, Hegge BJ, Masselink G (1999) Offshore wave climate, Perth (Western Australia), 1994-1996. Mar Freshw Res 50:95-102

Ling SD (2008) Range expansion of a habitat-modifying species leads to loss of taxonomic diversity: a new and impoverished state. Oecologia 156:883-894

Ling SD, Johnson CR, Frusher S, King CK (2008) Reproductive potential of a marine ecosystem engineer at the edge of a newly expanded range. Glob Change Biol 14:907-915

> Littaye A, Gannier A, Laran S, Wilson JPF (2004) The relationship between summer aggregation of fin whales and satellite-derived environmental conditions in the northwestern Mediterranean Sea. Remote Sens Environ 90:44-52

> Lourey MJ, Dunn JR, Waring J (2006) A mixed-layer nutrient climatology of Leeuwin Current and Western Australian shelf waters: seasonal nutrient dynamics and biomass. J Mar Syst 59:25-51

Mauna AC, Franco BC, Baldoni A, Acha EM, Lasta ML, Iribarne OO (2008) Cross-front variations in adult abundance and recruitment of Patagonian scallop (Zygochlamys patagonica) at the SW Atlantic shelf break front. ICES J Mar Sci 65:1184-1190

> McQuaid CD, Branch GM (1984) Influence of sea temperature, substratum and wave exposure on rocky intertidal communities: an analysis of faunal and floral biomass. Mar Ecol Prog Ser 19:145-151

Meuleners MJ, Ivey GN, Pattiaratchi CB (2008) A numerical study of the eddying characteristics of the Leeuwin Current System. Deep-Sea Res II 55:261-276

> Muhling BA, Beckley LE, Gaughan DJ, Jones CM, Miskiewicz AG, Hesp SA (2008) Spawning, larval abundance and growth rate of Sardinops sagax off southwestern Australia: influence of an anamalous eastern boundary current. Mar Ecol Prog Ser 364:157-167

O'Connor MI, Bruno JF, Gaines SD, Halpern BS, Lester SE, Kinlan BP, Weiss JM (2007) Temperature control of larval dispersal and the implications for marine ecology, evolution, and conservation. Proc Natl Acad Sci USA 104: 1266-1271

Pattiaratchi CB, Buchan SJ (1991) Implications of long-term climate change for the Leeuwin current. J R Soc West Aust $74: 133-140$ 
Pearce AF (1991) Eastern boundary currents of the southern hemisphere. J R Soc West Aust 74:35-45

Pearce A, Faskel F, Hyndes G (2006) Nearshore sea temperature variability off Rottnest Island (Western Australia) derived from satellite data. Int $\mathrm{J}$ Remote Sens 27: 2503-2518

Schils T, Wilson SC (2006) Temperature threshold as a biogeographic barrier in northern Indian Ocean macroalgae. J Phycol 42:749-756

Searle DJ, Semeniuk V (1985) The natural sectors of the inner Rottnest Shelf coast adjoining the Swan Coastal Plain. J R Soc West Aust 67:116-136

Smith RL, Huyer A, Godfrey JS, Church JA (1991) The Leeuwin Current off Western Australia. J Phys Oceanogr 21:323-345

Staehr PA, Wernberg T (2009) Physiological responses of Ecklonia radiata (Laminariales) to a latitudinal gradient in ocean temperature. J Phycol 45:91-99

Tuya F, Wernberg T, Thomsen MS (2008) Testing the 'abundant centre' hypothesis on endemic reef fishes in southwestern Australia. Mar Ecol Prog Ser 372:225-230

Vanderklift MA, Kendrick GA (2004) Variations in abundances of herbivorous invertebrates in temperate subtidal rocky reef habitats. Mar Freshw Res 55:93-103

Waite AM, Thompson PA, Pesant S, Feng M and others (2007)

Editorial responsibility: Hans Heinrich Janssen, Oldendorf/Luhe, Germany
The Leeuwin Current and its eddies: an introductory overview. Deep-Sea Res II 54:789-796

Wernberg T, Thomsen MS (2005) The effect of wave exposure on the morphology of Ecklonia radiata. Aquat Bot 83: $61-70$

Wernberg T, Coleman M, Fairhead A, Miller S, Thomsen M (2003a) Morphology of Ecklonia radiata (Phaeophyta: Laminariales) along its geographic distribution in southwestern Australia and Australasia. Mar Biol 143:47-55

Wernberg T, Kendrick GA, Phillips JC (2003b) Regional differences in kelp-associated algal assemblages on temperate limestone reefs in southwestern Australia. Divers Distrib 9:427-441

- Wernberg T, White M, Vanderklift MA (2008) Population structure of turbinid gastropods on wave-exposed subtidal reefs: effects of density, body size and algae on grazing behaviour. Mar Ecol Prog Ser 362:169-179

> Yokoyama R, Tanba S (1991) Estimation of sea surface temperature via AVHRR of NOAA-9 - comparison with fixed buoy data. Int J Remote Sens 12:2513-2528

Zainuddin M, Kiyofuji H, Saitoh K, Saitoh SI (2006) Using multi-sensor satellite remote sensing and catch data to detect ocean hot spots for albacore (Thunnus alalunga) in the northwestern North Pacific. Deep-Sea Res II 53: $419-431$

Submitted: March 26, 2009; Accepted: May 27, 2009 Proofs received from author(s): July 18, 2009 